Stevens, F., Zee, J. van der. Health care delivery systems. In: G.R. Ritzer (Ed.). The Blackwell encyclopedia of sociology. Londen: Blackwell, 2007. 2052-2058

\begin{tabular}{|l|l|}
\hline $\begin{array}{l}\text { Postprint } \\
\text { Version }\end{array}$ & 1.0 \\
\hline Journal website & \\
\hline Pubmed link & \\
\hline DOI & \\
\hline
\end{tabular}

This is a NIVEL certified Post Print, more info at http://www.nivel.eu

\title{
Health care delivery systems
}

\section{FRED STEVENS AND JOUKE VAN DER ZEE}

A health care delivery system is the organized response of a society to the health problems of its inhabitants. Societies choose from alternative health care delivery models and, in doing so, they organize and set goals and priorities in such a way that the actions of different actors are effective, meaningful, and socially accepted. From a sociological point of view, the analysis of health care delivery systems implies recognition of their distinct history over time, their specific values and value patterns that go beyond technological requirements, and their commitment to a set of normative standards (Parsons 1951; Selznick 1957). The term "system"' is used here in a sociological sense (Parsons 1951; Philipsen 1980). Typical system features are functional specificity (operational goals), structural differentiation (the division of labor), goal-setting (including effectiveness, efficiency), coordination (of activities, occupations, and facilities by mutual agreement, standards, or hierarchy), and boundary maintaining autonomy (in relation to political, economic, or normative structures). Some health care delivery systems comply more with these system characteristics than others. Where health care delivery systems vary, it is mainly due to longterm cultural and structural developments. Consequently, a health care delivery system is typified by its structure, its relationships between actors and organizations, and its specific pattern of underlying norms, values, and value orientations.

Three factors are significant in understanding the origins of modern health care delivery systems: (1) the socioeconomic level of development of a society, (2) its demographic situation, and (3) the epidemiological state of affairs. As shown in Table 1, modern societies developed from agricultural economies through industrialization to service economies in a societal transition. They initially focused on survival and self-sustenance of the small landholder and his or her (extended) family, but evolved toward economies creating surpluses (wealth) and added value to products that could be traded. Surpluses were commonly used to institute new roles and occupations that were important but not necessarily productive, such as priests, soldiers, tax collectors, and healers. Surpluses accumulated during long periods, in which stages of prosperity alternated with times of recession, due to war, famine, and pandemics. As societies further developed and modernized, more structures and institutions came into existence that reduced the risks of daily life.

Table 1 shows that widespread kinship-based arrangements to cope with these risks were gradually supplemented and replaced by collective arrangements. This culminated in a demographic transition consisting of the reduction of a population's fertility. In modern societies it was no longer imperative to have many children as a provision against old-age poverty. At the end of the nineteenth century, at first in Germany, social security systems against loss of income due to accidents and disabilities came into existence. These further developed to include public pension schemes several decades later. In addition to these collective arrangements, financial surpluses were the foundation of economic growth, by extending educational facilities, also creating more services and typical professions, like teachers, health care providers, lawyers, and engineers. In Europe, taxes or fee collection were the primary mechanisms and financial resources for these collective arrangements. In 
Stevens, F., Zee, J. van der. Health care delivery systems. In: G.R. Ritzer (Ed.). The Blackwell encyclopedia of sociology. Londen: Blackwell, 2007. 2052-2058

the course of this modernization process, the epidemiological transition took place that reflected a gradual shift from the sheer necessity to overcome infectious diseases (mainly affecting infants) toward dealing with chronic diseases (primarily affecting the late middle aged and elderly). Nowadays, health care delivery systems in modern societies are largely focused on the changing needs and demands of an aging population.

Health care organizations usually lag behind changing patterns of population needs. The reason is that modern, more sophisticated health care delivery systems, characterized by an advanced division of labor, high levels of complexity, and structural means for coordination and planning, require extensive financial resources. Yet only advanced economies are able to put aside sufficient resources for health care. Consequently, the extent to which resources can be generated for health care signifies a nation's stage of economic development. Evidently, on both micro (individual) as well on macro (societal) levels, there is a strong association between health and wealth. Several conclusions can be drawn. First, the wealth of a society is a major determinant of health. Second, it is more difficult to improve health in affluent societies than in poor ones. Third, in countries with low levels of income (usually typified as developing societies), hygiene, sanitation, vaccination, nutrition, and immunization are the important objectives for health care. Modern societies, with higher average levels of income, largely have to cope with rising costs due to the increasing demand for chronic care, as a consequence of an aging population.

\section{[TABLE 1]}

\section{TYPES OF HEALTH CARE DELIVERY SYSTEMS}

A simple, traditional market structure consists of bilateral relations between buyers and suppliers. The health care sector differs essentially from such a market structure, as interactions between actors are not organized in bidirectional relations of pairs of producers and consumers and the price of a health care procedure is not the balancing mechanism. Instead, health care delivery systems consist of five principal actors. These are the consumers (patients), first-line providers (usually general practitioners), second-line providers (hospitals, institutional facilities), the state, and insurers (Evans 1981). They are organized multi-directionally, as an interacting system. Dependent on organization and system features, consumers (1) have direct access to hospital services; (2) may need a referral from a GP; (3) get their health care expenses reimbursed from an insurer; (4) have total or partial health care insurance coverage and pay taxes or insurance premiums for that reason; or (5) have to pay their bill directly to the provider (like the simple market structure). Yet in typifying a nation's health system the role of the state in funding is decisive (Evans 1981; Hurst 1992; Marre'e \& Groenewegen 1997). Ideal typical ways of state funding involvement are:

- Largely absent: the state propagates noninterventionism, leaving room primarily for private insurance to fill this role. The organization and provision of health care in the US and Switzerland are typical examples.

- In-between: the state harmonizes the arrangements that developed between groups of citizens (e.g., employers, employees). This is the case in many European countries.

- Central: the state controls funding, with or without the provision of health care.

The former is/was typical of Eastern Europe and Russia; the latter is typical for the National Health Services (NHS) model as found in the UK.

The free market model applies when the state conducts a policy of non-interventionism and restricts its interference in health care matters to the bare essentials, leaving all other expenses to private funding and corporate provision (HMOs). This is the typical situation in the US, except for Medicaid (indigent) and Medicare (elderly) state interventions. Private insurance fills the gap to some degree, however, leaving about 16 percent of the US population uninsured for health care costs or loss of income due to illness and disability. 
Stevens, F., Zee, J. van der. Health care delivery systems. In: G.R. Ritzer (Ed.). The Blackwell encyclopedia of sociology. Londen: Blackwell, 2007. 2052-2058

The second model is the social insurance system, founded in the late nineteenth century in Germany. Typical for the social insurance system is that patients pay an insurance premium to a sickness fund which has a contract with firstline (GP) and second-line (hospital and specialist) providers. The role of the state is limited and confined to setting the overall terms of contracts between patients, providers, and insurers. The social insurance system is funded by premiums paid and controlled by employers and labor unions. These, however, have little control over the provision of services. This is left to the professions, specifically to the medical profession and to professionalized care organizations (e.g., home nursing, home help). For people with lower and middle-class salaried incomes, collective arrangements are available (sick funds). Founded in Germany, the social security model was almost immediately adopted by Czechoslovakia during Austrian-Hungarian rule, Austria, Hungary, and Poland. During World War II it was imposed on the Netherlands (1941) and later adopted by Belgium and France. The social insurance system survived two world wars and National Socialism, and in essence still exists in Germany, the Netherlands,

Belgium, France, Austria, Switzerland, Luxembourg, and Japan (Saltman \& Figueras 1997).

The third model, typically found in the UK, is the taxed-based National Health

Services (NHS) model. It was first introduced in 1948, is also centralized and is funded by means of taxation, while the state is responsible for the provision of institution-based care (hospitals). The medical profession has a rather independent position. Self-employed GPs are the gatekeepers in primary health care. Before visiting a hospital or a medical specialist one needs a referral from a GP. The NHS model leaves some room for private medicine. Through processes of diffusion and adaptation, the NHS model was first adopted in Sweden, and then by the other Nordic countries: Denmark, Norway, and Finland. At present, the NHS model applies to the United Kingdom, Ireland, Denmark, Norway, Sweden, Finland, Iceland, and outside Europe by Australia and New Zealand. Four Southern European countries have adopted, or are in the process of adopting, this tax-based model. These are Spain, Italy, Portugal, and Greece (Saltman \& Figueras 1997). The fourth, most centralized health care delivery systems model, the Soviet model, dates from 1920. It is characterized by a strong position of the state, guaranteeing full and free access to health care for everyone. This is realized by state ownership of health care facilities, by funding from the state budget (taxes), and by geographical distribution and provision of services throughout the country. Health services are fully hierarchically organized. They are provided by state employees, planned by hierarchical provision, and organized as a hierarchy of hospitals, with outpatient clinics (polyclinics) as lowest levels of entrance. Among the nations that, until recently, had a health care system based on the Soviet model were Russia, Belarus, the Central Asian republics of the former USSR, and some countries in Central and Eastern Europe. Many former Soviet Republics, however, are in a process of transition toward a social insurancebased system. The four models make up a continuum in terms of their "system"' character, with state interventionism and centralized health care at one end, and non-interventionism at the other. Centralized systems provide best mechanisms for cost control, while absence of state intervention does not appear to be fruitful, as soaring costs in the US evidently show. The four health delivery systems models are to be seen as pure types which can be found in many combinations and varieties. They also reflect stages and outcomes of a historical process. Consequently, system models that came into existence in highly developed economies in the first half of the twentieth century can now still provide useful options to choose from in developing countries or transitional economies like in Eastern European societies.

\section{HEALTH CARE DELIVERY SYSTEMS REFORM}

While the models presented reflect the major types that can be found in industrialized countries in Europe, the US, and Asia, none of these countries fully complies with the characteristics of one particular model. In a Weberian sense, they should be seen as ideal 
Stevens, F., Zee, J. van der. Health care delivery systems. In: G.R. Ritzer (Ed.). The Blackwell encyclopedia of sociology. Londen: Blackwell, 2007. 2052-2058

types. Through processes of adaptation and diffusion, national health care delivery systems deviate from these models. For example, social insurancebased health care delivery systems and the enterpreneurial system of the US were faced with problems of rising costs in the 1960s and 1970s. The NHS delivery systems and Sovietlike delivery systems of Eastern Europe had problems of neglect, underfunding, and extensive bureaucracy in the 1970 and 1980s. In some countries, specifically those with social security based health care systems, this has led to more state regulation to curb the costs of health care. In other countries it resulted in less state intervention, and in the introduction of different forms of managed competition. For example, in Eastern Europe, after the fall of the Berlin Wall, we see the demise of state funding and state provision due to economic deficits. In the countries that have adopted the social insurance model we see more state regulation in order to introduce more planning and to curb the rising costs of health care. One of the consequences has been a stronger position of hospitals. In the UK we have seen a movement towards more decentralization, which was realized by a separation between purchasers (the government) and providers (Saltman \& Figueras 1997; Tuohy 1999).

\section{CULTURAL ROOTS AND VALUE ORIENTATIONS}

Health care organization is also influenced by cultural circumstances. For example, nations with collective arrangements have more state intervention, a small private sector, a preference for tax rather than insurance funding, and comprehensive coverage with universal entitlement based on the notion of common rights. In contrast, societies steeped in individualism prefer private enterprise and insurance funding with selective coverage and high responsiveness to consumer demand. In societies which have equity as an important root we see explicit attempts to avoid discrimination and to facilitate public participation. In other words, values and value orientations play a role in the structuring of health care delivery systems. Anthropologists have argued that differences between health care delivery systems are embedded in the values and social structure of the societies involved (Helman 1996). Based on specific histories, traditions, customs, and so on, differences in health care organization reflect the way in which societies define and deal with issues of health and illness. Health and health care are embedded in value systems which give explanations why and how in specific cultures health problems are dealt with. For example, in some societies health care is considered a collective good for the benefit of all citizens. In other ones, health care is seen more as a "commodity" that can be bought or sold on a free market, or as an individual investment in human capital. As Gallagher (1988) notes: "The concept of health care as a calculable resource is an essential feature in its role as a carrier of modernity." The notion of health care as a commodity, however, has not been accepted everywhere. It seems to be more established in the essentially marketoriented organization of health care in the US than it is in Europe or Asia. Nowhere in Europe has it become part of health policy objectives. This is notwithstanding a wide range of health care reforms in recent years introducing market oriented approaches with incentives to introduce more competition between providers and to use resources more economically (Saltman \& Figueras 1997). Health care as a collective good for the benefit of all prevails in European health policy and in systems typified as national, social insurance, and so on. Health care as a commodity dominates in the US, although several European countries are moving in a similar direction. Cultures or nations can vary in value orientations to a considerable degree. For example, values of equity, solidarity, and autonomy may have different health care implications in different societies (Hofstede 1984). Emphasis on hospital care versus home care or care for the elderly, on individual responsibilities versus solidarity between people, reflect a society's general value orientations that have an impact on its health delivery systems model (Stevens \& Diederiks 1995; Saltman \& Figueras 1997; Philipsen 1980; Hofstede 1984). Or to put this differently, the free market, insurance, and taxbased health 
Stevens, F., Zee, J. van der. Health care delivery systems. In: G.R. Ritzer (Ed.). The Blackwell encyclopedia of sociology. Londen: Blackwell, 2007. 2052-2058

care delivery models to be found in the US, Germany, and the UK, respectively, are to a certain degree reflections of central values in their societies.

\section{CONVERGENCE AND DIVERGENCE}

There is ample evidence that contingencies like increasing health care costs, an aging population, changing disease patterns, technological developments, growing public demand, and so forth impose a common logic in terms of institutional performance and the structuring of modern health care. In the literature a wide range of convergencies in health policy and health care organization have been listed (Field 1989; Mechanic and Rochefort 1996; Raffel 1997; Saltman \& Figueras 1997). These include (1) the concern of governments to control health care costs while at the same time improving the effectiveness and efficiency of the system; (2) the increasing attention for health promotion and healthy lifestyles such as abstinence from substance use (alcohol, smoking, drugs), and healthy behavior; (3) reduction of health care inequalities and differences in access; (4) the stimulation of primary health care while cutting back extensive medical specialization; (5) the promotion of patient involvement in care and treatment and improving patient satisfaction; and (6) the reduction of fragmentation of services and the promotion of continuity of care.

Yet the convergence of modern health care delivery systems is not undisputed. Even if societies are faced with similar contingencies, their societal structures have to be consonant with culturally derived expectations (Lammers \& Hickson 1979). Consequently, while there is substantial evidence that modern societies are evolving into the same direction with efficiency equity and utilitarian individualism as core value orientations, differences exist in degree and similarity of these developments. Modern societies still vary considerably in their dealing with issues of health and illness (Anderson et al. 1995). Moreover, while nations may have similar goals, alternative options are available to reach these. National health delivery systems are the outcome of a dialectical tension between universal aspects of technology and medicine on the one hand, and particularistic cultural characteristics of each nation on the other (Field 1989). These particularistic cultural characteristics refer to the historical foundations of health care delivery systems, to the societal and national context, and to specific values and value orientations of societies and health care delivery systems under consideration. Health care institutions are still largely country specific (Pomey \& Poullier 1997). Such country specific elements would include social, economic, institutional, and ideological structures, the dominant belief system, the role of the state versus the market, patterns of health care coverage, and centralization or decentralization of political authority (Saltman \& Figueras 1997, 1998).

\section{SEE ALSO:}

Health and Culture; Health Maintenance Organization; Health Professions and Occupations; Health and Social Class; Hospitals; Socialist Medicine; Socialized Medicine

\section{REFERENCES AND SUGGESTED READINGS}

Anderson, J. G., Oscarson, R., \& Yu, Y. (1995) Japan's Health Care System: Western and East Asian Influences. In: Gallagher, E. \& Subedi, J. (Eds.), Global Perspectives on Health Care. Prentice-Hall, Englewood Cliffs, NJ, pp. 32-44.

Evans, R. G. (1981) Incomplete Vertical Integration: The Distinctive Structure of the HealthCare Industry. In: Van der Gaag, J. \& Perlman, M. (Eds.), Health, Economics, and Health Economics: Proceedings of the World Congress on Health Economics, Leiden, The Netherlands, September 1980. North-Holland, Amsterdam, pp. 329-54.

Field, M. (1989) The Comparative Evolution of Health Systems: Convergence, Diversity and Cross-Cutting Issues. In: Lu"schen, G., Cockerham, W., \& Kunz, G. (Eds.), Health and Illness in America and Germany. Oldenbourg, Munich, pp. 15-30. 
Stevens, F., Zee, J. van der. Health care delivery systems. In: G.R. Ritzer (Ed.). The Blackwell encyclopedia of sociology. Londen: Blackwell, 2007. 2052-2058

Gallagher, E. B. (1988) Modernization and Medical Care. Sociological Perspectives 31: 5987.

Helman, C. G. (1996) Culture, Health and Illness. Wright, London.

Hofstede, G. (1984) Culture's Consequences: International Differences in Work-Related

Values. Sage, London.

Hurst, J. (1992) The Reform of Health Care: A Comparative Analysis of Seven OECD Countries. Organization for Economic Cooperation and Development, Paris.

Lammers, C. J. \& Hickson, D. J. (1979) Organizations Alike and Unlike: International and InterInstitutional Studies in the Sociology of Organizations. Routledge \& Kegan Paul, London.

Lüschen, G., Cockerham, W., Van der Zee, J., et al. (1995) Health Systems in the European Union. Oldenbourg, Munich.

Marrée, J. \& Groenewegen, P. P. (1997) Back to Bismarck: Eastern European Health Care in Transition. Avebury, Aldershot.

Mechanic, D. \& Rochefort, D. A. (1996) Comparative Medical Systems. Annual Review of Sociology 22: 239-70.

Parsons, T. (1951) The Social System. Free Press, New York.

Philipsen, H. (1980) Internationale vergelijking van welvaart, gezondheidszorg en levensduur: het probleem van Galton. Gezondheid en Samenleving 1: 5-17.

Philipsen, H. (1995) Gezondheid en gezondheidszorg in Belgie" en Nederland. Gezondheid en Samenleving 5: 223-31

Pomey, M. \& Poullier, J. (1997) France. In: Raffel, M. (Ed.), Health Care and Reform in Industrialized Countries. Pennsylvania State University Press, University Park.

Raffel, M. W. (1997) Dominant Issues: Convergence, Decentralization, Competition, Health Services. In: Raffel, M. (Ed.), Health Care and Reform in Industrialized Countries. Pennsylvania State University Press, University Park, pp. 291-303.

Saltman, R. B. \& Figueras, J. (1997) European Health Care Reform. WHO Regional Publications, European Series. World Health Organization, Regional Office for Europe, Copenhagen.

Saltman, R. B. \& Figueras, J. (1998) Analyzing the Evidence on European Health Care Reforms. Health Affairs 17: 85-105.

Selznick, P. (1957) Leadership in Administration. Harper \& Row, New York. Stevens, F. C. J. \& Diederiks, J. P. M. (1995) Health Culture: An Exploration of National and Social

Differences in Health-Related Values. In: Lüschen, G., Cockerham, W., Van der Zee, J., et al. (Eds.), Health Systems in the European Union. Oldenbourg, Munich, pp. 75-88.

Tuohy, C. H. (1999) Dynamics of a Changing Health Sphere: The United States, Britain, and Canada. Health Affairs 18: 114-31. 
Stevens, F., Zee, J. van der. Health care delivery systems. In: G.R. Ritzer (Ed.). The Blackwell encyclopedia of sociology. Londen: Blackwell, 2007. 2052-2058

\section{TABLES}

Table 1 Societal transitions and the development of health care delivery systems.

\begin{tabular}{|c|c|c|c|c|c|c|}
\hline \multirow[t]{2}{*}{$\begin{array}{l}\text { Societal } \\
\text { transition }\end{array}$} & $\begin{array}{l}\text { AGRICULTURE } \\
\text { (rural) }\end{array}$ & \multirow[t]{2}{*}{$\longrightarrow$} & $\begin{array}{l}\text { INDUSTRY } \\
\text { (urban) }\end{array}$ & \multirow{2}{*}{\multicolumn{2}{|c|}{$\longrightarrow$}} & $\begin{array}{l}\text { SERVICES } \\
\text { (suburban) }\end{array}$ \\
\hline & $\begin{array}{l}\text { Multi-generation } \\
\text { family }\end{array}$ & & $\begin{array}{l}\text { Nuclear } \\
\text { family }\end{array}$ & & & $\begin{array}{l}\text { Individual } \\
\text { households }\end{array}$ \\
\hline \multicolumn{7}{|c|}{ Social tensions, revolutions, war } \\
\hline \multirow{3}{*}{$\begin{array}{l}\text { Main } \\
\text { health } \\
\text { issues }\end{array}$} & \multicolumn{6}{|c|}{ Demographic transition } \\
\hline & $\begin{array}{l}\text { Infectious } \\
\text { diseases }\end{array}$ & & $\begin{array}{l}\text { Declining } \\
\text { fertility }\end{array}$ & $\begin{array}{l}\text { Aging } \\
\text { population }\end{array}$ & $\longrightarrow$ & $\begin{array}{l}\text { Chronic } \\
\text { diseases, } \\
\text { diseases of } \\
\text { civilization }\end{array}$ \\
\hline & $\begin{array}{l}\text { Declining } \\
\text { mortality }\end{array}$ & & & \multicolumn{3}{|c|}{ Epidemiological transition } \\
\hline $\begin{array}{l}\text { Focus } \\
\text { of care }\end{array}$ & $\begin{array}{l}\text { Hygiene, } \\
\text { public health, } \\
\text { informal care }\end{array}$ & $\longrightarrow$ & $\begin{array}{l}\text { Emerging } \\
\text { curative } \\
\text { care, social } \\
\text { security, } \\
\text { welfare state }\end{array}$ & & & $\begin{array}{l}\text { High tech care, } \\
\text { professional } \\
\text { home care }\end{array}$ \\
\hline
\end{tabular}

